\title{
JORGE DE LIMA DÁ LICENÇA PARA QUE EU...?
}

\author{
Ângela Maria de Pinho e Silva*
}

RESUMO:

A poesia negra de Jorge de Lima é um retrato lírico dentro do movimento regionalista nordestino. Lima enfatiza o folclore e temas religosos em poemas negros e alguns livros de sua fase regionlista.

PALAVRAS-CHAVE: poesia negra nordestina, Jorge de Lima, poeta múltiplo, geografia humana e social do Nordeste brasileiro.

As inúmeras vocações de Jorge de Lima e sua inquietude criadora possibilitam-nos considerá-1o expressão da alteridade pela via da multiplicidade. Vemo-10 perfazer um caminho em que a mutabilidade estética permitia-lhe expressar uma gama de eus artísticos, marcados pela diferença no contexto de suas composições. Parece-nos haver uma consciência organizadora das identidades várias, para a expressão da diversidade criativa em Jorge de Lima. Num trecho de uma de suas entrevistas, o seguinte:

Ora, o poeta, como toda criatura, é espiritualmente múltiplo, cruzam-se
nele contraditórias ondas de almas de modo que no âmago de cada ser podem
achar-se, em campos opostos, numerosas entidades anímicas, combatendo sem
trégua. Filosofias, seitas, programas políticos, nada mais têm feito que
tentar conseguir para o contraponto biológico e metafísico um núcleo de
satisfatória aglutinação de espíritos e corpos. (Lima, 1997: 47).
Intentemos apreender o que seria aglutinação de espíritos e corpos. Reunir as disparidades do anímico às disparidades do espiritual? Jorge de Lima, para quem a poesia "será sempre uma revelação de Deus, dom, gratuidade, transcendência, vocação" (Lima, 1997: 36), empreende desenvolver esse dom inquietante, talvez

| Mestre em Letras: Estudos Literários (Ârea de concentração: Literatura Brasileira), 2003. 


\section{EMTESE}

Belo Horizonte, v. 8, p. I-243, dez. 2004

buscando sossegar uma certa nostalgia da unidade. Pode-se crer que a cultura africana constituísse uma dessas entidades anímicas e metafísicas que o autor tentou aglutinar ao seu mundo cultural. A expressividade de suas composições afronordestinas faz-nos acreditar que a sua intenção seria entrelaçar as disparidades culturais no âmago do ser múltiplo.

0 aspecto da heterogeneidade de certas posições assumidas pelo sujeito lírico diante do objeto poético e a característica essencialmente movediça dessas posições permitem-nos considerar Jorge de Lima um poeta fundamentalmente experimental, que teria subjugado sua vocação às variadas experiências empreendidas: experimentando a linguagem, a forma, a musicalidade, a própria língua, e, às vezes, línguas estrangeiras. Vários temas e motivos foram explorados no laboratório de "poesia experiência"1 de Jorge de Lima.

Nossas reflexões a respeito do recorte escolhido - "A poesia afronordestina de Jorge de Lima" (assunto da dissertação de mestrado - maio de 2003) propiciaram-nos detectar as imbricações dos discursos - poético e sociológico - e as implicações ideológicas subjacentes a eles e, nesse sentido, atentamos à nãoneutralidade da linguagem. Contudo, queríamos eximir Jorge de Lima da pecha de preconceituoso. Relutávamos em admitir que a sua poética ou que o seu discurso literário reproduzia os pensamentos, as ideologias assimiladas do contexto cultural ao qual ele pertencia. Esquecíamos que a consciência cultural e crítica manifestase através da sutileza do discurso. Reconhecemos, afinal, que a afeição artística pelo negro não teria possibilitado a Jorge de Lima um meio de se desvencilhar das determinantes aristocráticas que marcariam a sua poética onde o negro figurou como o execrado principalmente pela sua cor $^{2}$.

A partir dessas constatações, vimos que o negro, na poética de Jorge de Lima, é representado ora pela simpatia, ora reproduzindo a ideologia da classe social dominante. A ambivalência dessas posições pareceu-nos um processo inconsciente, pois o poeta as mantinha, quase sempre, num mesmo poema. Poemas, como, por exemplo, "Zumbi" (Lima, 1997:184-185), "Pai João" (p.245) e "01á! negro" (p.315-317), manifestam simpatia consorciada à representação do preconceito. Exaltam-se os predicados da raça negra, mas o arrebatamento poético perde-se quando aparecem as expressões preconceituosas. Reconhecemos que a poética limiana apenas "reduplicava poeticamente 
uma ideologia presente nos textos que já tratavam o assunto", conforme assinala Dulce Maria Viana (Viana, 1987: 342)33.

Por ora passaremos ao texto escolhido para apresentarmos Jorge de Lima, pedindo-1he licença para fazê-10 à nossa maneira.

Extraímos os dois versos finais do poema - "Janaína" (Poemas negros). Ei-1os:

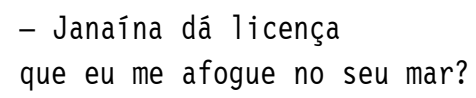

Por minha vez, peço: Jorge de Lima, dá licença que eu me adentre no solo do Nordeste brasileiro, que eu percorra alguns caminhos, veja algumas personagens, certos lugares, enfim, que eu conheça um pouco desse mundo de seu imaginário poético, dá licença?

Permita-me conhecer União dos Palmares, a antiga Cerca-rial-de-macacos, Vila Imperatriz, Madalena (Cavalcanti, 1969: 14-15), quantos nomes teve esta cidade?

0 rio Mandaú, O A B C de sua meninice, aquele que você desceu e nunca mais subiu (Lima, 1997: 231).

Sei que não é possível encontrar Zumbi dos Palmares, mas a sua história é recontada, nestes versos:

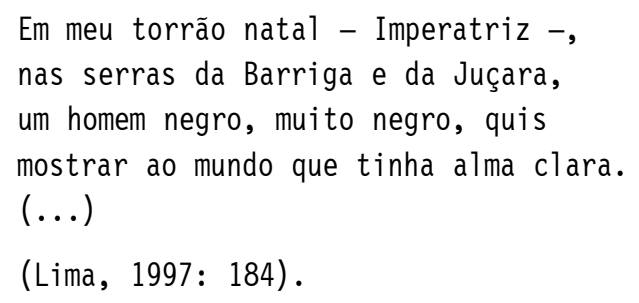

0 quarto verso dessa estrofe muito me incomoda. Vou substitui-10 por: mostrar ao mundo a alma de sua raça (rimou com Juçara, rima interna?). Também não gosto dos dois versos finais da última estrofe:

faz-se em pedaços para que não fique com os homens brancos, o seu negro rastro...

Dá licença para que eu possa transmutar a negativa em afirmativa e mudar o último verso? Ficaria assim: faz-se em pedaços para que apenas fique/com os homens 


\section{EMTESE}

brancos, a culpa deste rastro. Desculpa-me essa experiência com o poético! Acontece que quando leio essas expressões preconceituosas, as elimino. Elas não combinam com o tom laudativo do poema.

Desejo passear pela serra da Barriga. Rever a mesma paisagem que o impressionou tanto. Pretendo subi-la e, lá de cima, olhar o sobrado onde você nasceu. Ver o rio Mandaú e tudo mais. 0 que divisarei atrás da serra? Palmares? Zumbi não se encontra mais 1á. No poema "Serra da Barriga" (Lima, 1997: 257-258), o quilombo dos Palmares representa-se pela figura do herói mítico da Tróia negra. A geografia física e humana é lindamente descrita. Leiamos alguns versos:

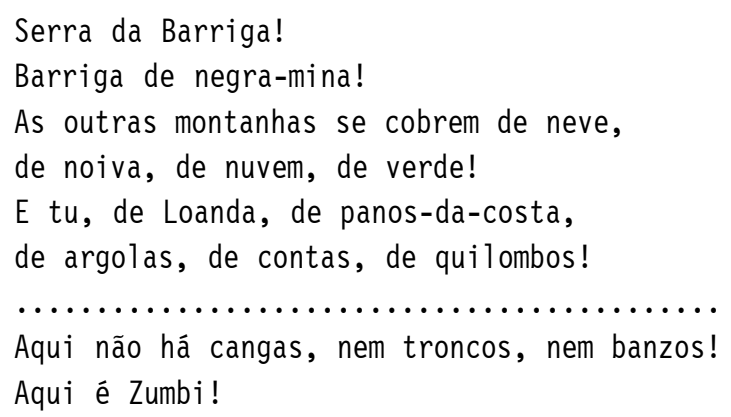

Deixemos a serra, voltemos à União dos Palmares. Procuremos Joaquina maluca, aquela que enlouqueceu, mas conservou a graça de menina (Lima, 1997: 266). Por Celidônia, não the perguntarei, sei que o seu desejo é recalcar a perda dessa maga primeira, pois, o refrão de "Ancila negra" constitui-se da palavra recalcar, sugerindo-nos que esse é o desejo do sujeito lírico. Recalcar as recordações, não deixar que elas fluam. Todavia, as lembranças são extensivamente reapresentadas, talvez numa tentativa de recuperar o passado através da linguagem poética:

Há muita coisa a recalcar e esquecer.

(Lima, 1997: 303-306).

Celidônia era "carne perdida, /noite estancada, /rosa trigueira, / maga primeira", seria difícil esquecê-la. Não se trata de descrever ou narrar acontecimentos observados ou conhecidos. Quem sofre não é Zumbi, Fulô, Pai João ou qualquer outro elemento da raça negra. Trata-se de retratar a negra Celidônia. Ela é-nos apresentada como a amiga, recebe tratamento diferente das demais negras que figuram na poética limiana. 
Não encontramos nenhuma conjunção adversativa nem qualquer outro vocábulo que possa representar preconceito disfarçado. Celidônia é a escrava negra. É linda. É lembrança sempre evocada. As evocações engendram as cenas que se desencadeiam revelando-nos os fatos. "Ancila negra" apresenta-nos um poeta arrebatado e participante.

Poeta, interessa-me conhecer a G.W.B.R., a estrada de ferro feita de encomenda para o Nordeste. Posso me instalar naquele trem e da janela ver todo o trajeto que você percorreu na sua "viagem deslumbrada"? Antes, porém, gostaria de perguntar-1he: como conseguiu destruir todos os brinquedos? Aqueles do poema "0 menino impossivel" (Lima, 1997:203-205). Fala-se que a sua adesão ao Modernismo rendeu-The críticas e aplausos. Posso imaginar, também, destruir todos aqueles brinquedos! Ainda mais depois de ser eleito "o príncipe dos poetas alagoanos" com o seu soneto "0 acendedor de lampiões" (p.192), poema parnasiano, alexandrino. A glória de ser príncipe não o impediu de pegar o trem do Modernismo, não é mesmo? Foi uma mudança digna de um nordestino de fibra e com ela inicia-se uma nova fase de sua poesia.

Façamos a viagem pelo pitoresco Nordeste, através da G. W. B. R., a estrada feita de encomenda para os "bemóis de sua alma lírica" (Lima, 1997: 219225). 0 poema mostra-nos como o poeta incorporou as novas aquisições estéticas, conservando seu lirismo singular. Leiamos alguns de seus versos:

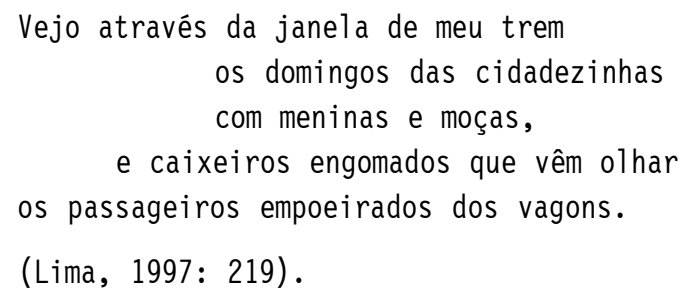

Deixemos a estrada. Pretendo conhecer pessoas. Apresente-me a uma Zefa, qualquer uma delas. Zefa do "Inverno" (Lima, 1997:261-262): "tempo gostoso"! Mário Faustino assinala que o poder de evocação deste poema é milagroso (Faustino, 1977: 222). Gosto especialmente da Zefa do romance $A$ mulher obscura, ouvindo aquele solilóquio de Fernando (personagem central) e em seguida a cena do banho das negras. Inusitada a descrição do banho das "Zefas", leiamos um trecho:

Depois de lavar a roupa dos outros, Zefa lava a roupa que a cobre no momento. Depois, deixa-a corando sobre o capim. Então Zefa-Lavadeira ensaboa o seu 


\section{EMTESE}

Belo Horizonte, v. 8, p. I-243, dez. 2004

próprio corpo, vestido do manto da pele negra com que nasceu. Outras Zefas, outras negras, vêm lavar-se no rio. Eu estou ouvindo tudo, eu estou enxergando tudo. Eu estou relembrando a minha infância. A água, levada nas cuias, começa 0 ensaboamento; desce em regatos de espuma pelo dorso e some-se entre as nádegas rijas. (Lima, 1998:81).

Isso é prosa ou poesia? Talvez nem o poeta soubesse porque decidiu inserir o texto do romance em Poemas negros (Lima, 1997: 301-302). "0 banho das negras" também foi enxerto do mesmo romance para o livro de poemas de 1947 (Lima, 1997: 306-307).

Desejo conhecer um bangüê. Se não existe nenhum mais em Alagoas, contentarme-ei com a leitura de alguns versos do seu poema "Bangüê". Com esses principalmente:

0 meu bangüezinho era tão diferente, vestidinho de branco, o chapeuzinho do telhado sobre os olhos, fumando o cigarro do boeiro para namorar a mata virgem.

(Lima, 1997: 296-297).

Os versos de "Bangüê" fazem-nos voltar ao tempo dos engenhos. A produção do açúcar e/ ou da cachaça. Existirá algum adulto que uma vez haja presenciado uma cena daquelas: a moenda da cana, a garapa, a tacha cheia de melado borbulhando, que não passe imediatamente às recordações de sua meninice perdida? Nem é necessário ser nordestino, os mineiros também possuíram seus engenhos. Que doçura de Brasil! É isto que "Bangüê" recria: a geografia física e humana dos engenhos.

Desejo ir a um xangô. Que seria um xangô? Lembramos que, segundo Jorge de Souza Araújo, no seu glossário de termos afro-nordestinos encontrados na poesia de Jorge de Lima, xangô é o mesmo que catimbó (Araújo, 1983: 152).

"Xangô"4 é um dos mais expressivos poemas da temática candomblezeira. Incorpora elementos da miscigenação cultural representando a ambiência em que os cerimoniais mítico-religiosos acontecem. Leiamos alguns de seus versos. A primeira estrofe:

Na noite, aziaga, na noite sem fim, quibundos, cafusos, cabindas, mazombos mandigam xangô. 0xum! Oxalá. ô! Ê!

(Lima, 1997:312). 
0 núcleo da poética de Jorge de Lima pode não ser a verossimilhança. É possível que a religiosidade da raça negra transportada para seus textos represente vivências do poeta, retalhadas de suas impressões pessoais. Acreditamos que o autor haja se servido mais de sua imaginação do que representado os ritos como eles se desenvolvem nas cerimônias dos xangôs alagoanos. Que nos importa? 0 poema não se presta a esse dizer que tudo investiga sem descaracterizar a verdade.

A respeito de uma possível descaracterização da ambiência dos xangôs e dos cerimoniais representados na poética limiana, assevera-nos Jorge Araújo de Souza:

Sem dúvida, alguns desvios no poema se devem, talvez, à fisiografia dos xangôs deformados da primitiva pureza, fenômeno que deve ter ocorrido no Nordeste, ou talvez ao gozo inconseqüente do poeta em acentuar características de magia negra ao culto (Araújo, 1983: 175).

Acreditamos que o poema se realiza dentro dessas possibilidades: a) a experiência com o poético deu-se pela observação dos rituais já desvirtuados de suas características primitivas; b) o poeta desconhecia as deformações ocorridas. Provavelmente reconstitui a ambiência mítica dos cultos africanos sem intenção de descaracterizá-1a. Talvez tentasse incorporar vivências pessoais às experiências poéticas. Nada impede que as haja impregnado de doses extras de imaginação. Seja como for fica-nos uma impressão de verossimilhança.

Por outro lado, poemas como "Xangô", "Quando ele vem" (Lima, 1997: 311312) "Obambá é batizado" (Lima, 1997: 308-309) e outros em que a religiosidade dos afro-nordestinos é representada, inserem os ritmos peculiares dos tambores africanos. 0s tantãs ressoam através do emprego de termos do vocabulário africano. Possuem tais poemas prerrogativas que se constituem em esferas rítmico-auditivo-visuais. 0 léxico africano produz ou reproduz os desdobramentos sonoros. Há uma representação mimética presentificadora da cultura africana. A tonalidade estabelece-se pela ressonância das combinações experimentadas. A leitura desses poemas requer uma atitude corporal ativa. Parece-nos que a mandinga realiza-se na forma e na temática produzindo um efeito sinestésico.

Se os elementos da liturgia católica e das crenças africanas imbricamse de tal forma que os orixás do panteão africano e os santos do catolicismo são indistintamente solicitados para a mandinga em questão, os elementos lingüísticos 


\section{EM TESE}

Belo Horizonte, v. 8, p. I-243, dez. 2004

poetizam o candomblé trazendo-o ao leitor como um ato de uma mandinga específica a feitiçaria do dizer poético.

Se detectarmos inverossimilhanças nas representações poéticas de Jorge de Lima nesse universo cultural dos afro-nordestinos, nunca deixaremos de encantarnos evidentemente com a expressividade dessas composições. Ressaltamos que a contribuição de Jorge de Lima à poesia afro-brasileira é relevante e revela-nos a possibilidade da aproximação da cultura brasileira à cultura africana, a possibilidade da construção de uma cultura mestiça, crioula.

NOTAS:

1. Mário Faustino, em seu livro Poesia-experiência, dedica a Jorge de Lima o ensaio "Revendo Jorge de Lima" (Faustino, 1977: 219-274). Entre outras preciosidades afirmanos o crítico: "Jorge de Lima tentou muitos saltos, quase sempre difíceis, errou a maioria mas acertou vários, alguns espetaculares - e foi fértil ao longo de toda a sua acidentada corrida de obstáculos" (Faustino, 1977: 274).

2. No poema "01á! Negro" (Poemas negros), o negro é execrado em função da sua cor. Vê-se que 0 autor não se desvencilhou das determinantes culturais da sociedade brasileira que discrimina a raça negra pelos caracteres fenótipos principalmente.

3. 0 artigo intitula-se "0 estatuto da ambigüidade: Jorge de Lima e a escravidão". Tratase de uma análise das implicações dos discursos que se constroem pela contigüidade metonímica de discurso para discurso.

4. "Xangô" teve uma versão anterior que aparece em Poemas (1927). 0 poema volta a Poemas negros numa $2^{\mathrm{a}}$ versão, em que são retirados estrofes inteiras e alguns versos. Desconhece-se qualquer razão para essas mudanças. Acredita-se que o poeta haja modificado o poema para retirar expressões preconceituosas em relação ao negro. (Cf. a primeira versão in: Lima, 1997: 226-229).

ABSTRACT:

The Negro poetry of Jorge de Lima is a lyric portraiture within the North-eastern Regionalist Movement. Lima emphasizes folklore and religious themes in Negro poems and some books of his regional phase.

KEY WORDS: Northeastern Afro-poetry, Jorge de Lima, multiple poet, human and social geography of the Brazilian Northeast. 


\section{REFERÊNCIAS BIBLIOGRÁFICAS}

ARAÚJ0, Jorge de Souza. Jorge de Lima e o idioma poético afro-nordestino. Maceió: EDUFAL, 1983.

CAVALCANTI, Povina. Vida e obra de Jorge de Lima, Rio de Janeiro: Correio da Manhã, 1969, p. 14-23.

FAUSTINO, Mário. "Revendo Jorge de Lima". In: Poesiaexperiência, São Paulo: Perspectiva, 1977, p. 219-274.

LIMA, Jorge de. Jorge de Lima: poesia completa, Rio de Janeiro: Nova Aguilar, 1997.

VIANA, Dulce Maria. "0 estatuto da ambigüidade: Jorge de Lima e a escravidão". Revista de Letras, Fortaleza, 12(1/2) [jan./dez. 1987: 341-356]. 